\title{
SPECTROSCOPIC STUDY OF RARE EARTH CHROMATES: RELATION TO THE STRUCTURE
}

\author{
E. Antic-Fidancev, M. Lemaitre-Blaise \\ Laboratoire de Chimie Métallurgique et Spectroscopie des Terres Rares \\ CNRS-UPR209 1, Place A. Briand, 92195 Meudon, France \\ AND C. Parada \\ Dpto de Quimica Inorganica, Faculdad de Quimicas \\ Universidad Complutense, 28040 Madrid, Spain
}

\begin{abstract}
The luminescence spectra of the trivalent europium ion embedded in various rare earth chromates were analyzed. The spectroscopic data in most of chromates are in agreement with the structural determination but for some others the discrepancy between two methods is underlined. Energy level schemes were deduced from the experimental emission spectra and the crystal field simulation has been performed. The maximum splitting of the ${ }^{7} F_{1}$ manifold of the $\mathrm{Eu}^{3+}$ ion as a function of $N_{v}$, the so-called crystal field strength parameter, is given. This allows us to classify the compounds according to their crystal field extent.
\end{abstract}

PACS numbers: 33.50.Dq, 33.50.Hv, 71.70.Ch, 78.50.Ec

\section{Introduction}

In the course of our study in the research of efficient rare earth phosphors new compounds were synthesized under hydrothermal conditions or by solid state reaction. Therefore, in the ternary system $\mathrm{RE}_{2} \mathrm{O}_{3}-\mathrm{CrO}_{3}-\mathrm{M}_{2} \mathrm{O}(\mathrm{RE}=$ rare earth, $\mathrm{M}=$ alkali metal) different chromates studied here by luminescence spectroscopy are the following: double chromates with the potassium, $\operatorname{KRE}\left(\mathrm{CrO}_{4}\right)_{2},[1,2]$; hydroxo-chromates, $\mathrm{RE}(\mathrm{OII}) \mathrm{CrO}_{4}, \quad[3]$ and seven hydrated chromates $\mathrm{RE}_{2}\left(\mathrm{CrO}_{4}\right)_{3}, 7 \mathrm{II}_{2} \mathrm{O}[4]$. They crystallize in the monoclinic or orthorhombic system and the rare earth atom is situated in one point site of very low symmetry in all these chromates except in the last one for which two different environments were found for the lanthanide ion.

It is well known that the compounds in the lanthanide series can show different structures as a consequence of the decrease in the ionic radii. Moreover, the decrease in the ionic radii can lead to a reduction in the coordination number around the lanthanide cation [5]. It is the case of the rare earth chromates. 
We report here the optical properties and the simulation of the energy level scheme of trivalent europium ion embedded in the rare earth chromates studied and discuss their relation to the crystal structures previously determined [1-4]. The present work underlines the sensitivity of the spectroscopy for the characterization of new phases.

\section{Synthesis and crystallographic background}

\section{1. $\mathrm{KRE}\left(\mathrm{CrO}_{4}\right)_{2}$}

The double chromates of rare earth and potassium cation with a general formula $\mathrm{KRE}\left(\mathrm{CrO}_{4}\right)_{2}$ were obtained by a hydrothermal synthesis method at low temperature $\left(120-150^{\circ} \mathrm{C}\right)$ in sealed glass tubes during one month or by direct reaction in air between the stoichiometric proportions from a finely ground mixture of potassium chromate and rare earth oxides, $\mathrm{K}_{2} \mathrm{Cr}_{2} \mathrm{O}_{7} / \mathrm{RE}_{2} \mathrm{O}_{3}$.

In the lanthanide series three different structural types were found. Compounds with heavy rare earths ( $\mathrm{La}-\mathrm{Eu})$, constitute the first isostructural series. For that series the monoclinic structural type belongs to the $P 2_{1} / c$ space group $\left(\mathrm{N}^{\circ} 14\right)$. In that phase the lanthanum ion, nine-fold coordinated, (La-O distances between 2.51 and $2.761 \AA$ ) is located in $\left(\mathrm{La}\left(\mathrm{CrO}_{4}\right)_{2}{ }_{n}^{n-}\right.$ layer perpendicular to the $a$ crystallographic axis [1]. Each layer is built by double rows of $\mathrm{CrO}_{4}^{-2}$ tetrahedra linked to the lanthanum atom through oxygen atoms. The $\mathrm{K}^{+}$ions are situated between these layers. All atoms occupy the general $4 e$ position in the crystal lattice. There is only one site of very low symmetry, $\left(C_{1}\right)$, for the rare earth ion.

In the middle of the rare earth series ( $\mathrm{RE}=\mathrm{Eu}, \mathrm{Gd}$ and $\mathrm{Tb}$ ) another phase with the orthorhombic structure is found, belonging to the $P 2_{1} 2_{1} 2_{1}$ space group (No19) [2]. The structure consists of $\mathrm{CrO}_{4}$ tetrahedra and $\mathrm{REO}_{8}$ distorted bicapped trigonal prisms sharing corners and forming channels parallel to the $b$ axis. The rare earth ion is eight-fold coordinated, ( $\mathrm{Eu}-\mathrm{O}$ distances are between 2.25 and $2.74 \AA$, for example). According to the crystallographic analysis the rare earth ion occupies here also one point site of low symmetry, $C_{1}$.

At the end of the rare earth series a third structural modification was found and determined as monoclinic one [6]. The optical analysis were not realized on that series. This class of compounds will not be considered in the following.

\section{2. $\mathrm{RE}(\mathrm{OH}) \mathrm{CrO}_{4}$}

The rare earth hydroxo-chromates with a general formula $\mathrm{RE}(\mathrm{OII}) \mathrm{CrO}_{4}$ were obtained from $\mathrm{RE}_{2} \mathrm{O}_{3}, \mathrm{CrO}_{3}$ and $\mathrm{Li}(\mathrm{OII})$ in molar ratios $1: 4: 3$, by hydrothermal synthesis for $40 \mathrm{~h}$ at $130^{\circ} \mathrm{C}$ in sealed Pyrex glass tubes. They form one isostructural series for heavy lanthanides ( $\mathrm{RE}=\mathrm{La}-\mathrm{Nd}$ ) and crystallize in the monoclinic system, space group $P 2_{1} / n$. The rare earth ion occupies one site of low symmetry, $\left(C_{1}\right)$, in the structure and is nine-fold coordinated (La-O distances: 2.467 to $2.729 \AA$ ). The structure $\mathrm{RE}(\mathrm{OH}) \mathrm{CrO}_{4}$ consists in three-dimensional array in which the tetrahedral $\mathrm{CrO}_{4}$ groups alternate with $\mathrm{REO}_{9}$ polyhedra [3]. 


\section{3. $R E_{2}\left(\mathrm{CrO}_{4}\right)_{3}, 7 \mathrm{H}_{2} \mathrm{O}$}

Seven hydrated rare earth chromate phases with a general formula $\mathrm{RE}_{2}\left(\mathrm{CrO}_{4}\right)_{3}, 7 \mathrm{II}_{2} \mathrm{O}$, exist for $\mathrm{RE}=\mathrm{La}-\mathrm{Gd}$. The single crystals were grown by hydrothermal procedure from an aqueous solution of rare earth oxide, chromium oxide and lithium hydroxide in molar ratios $1: 4: 3$, respectively, for 4 hours at $125^{\circ} \mathrm{C}$ [4]. The compounds exhibit the monoclinic structure, space group $P 2_{1} / n$, with two different crystallographic sites for the rare earth atoms both in nine coordination (Fig. 1a, for RE $=\mathrm{Sm}$ ). The two $\left(\mathrm{REO}_{9}\right)$ units will be noted (RE1) and (RE2) in the following. The structure is formed by alternated units of (RE1) and (RE2) bridged by the chromate groups along the $b$ axis (Fig. 1b, for RE = $\mathrm{Sm})$. The rare earth oxygen distances $\mathrm{RE}-\mathrm{O}$ for two samarium atoms are: 2.35 to 2.60 and 2.37 to $2.56 \AA$ for $\mathrm{Sm} 1$ and $\mathrm{Sm} 2$,respectively.

Lattice parameters for several rare earth chromates are collected in Table I.
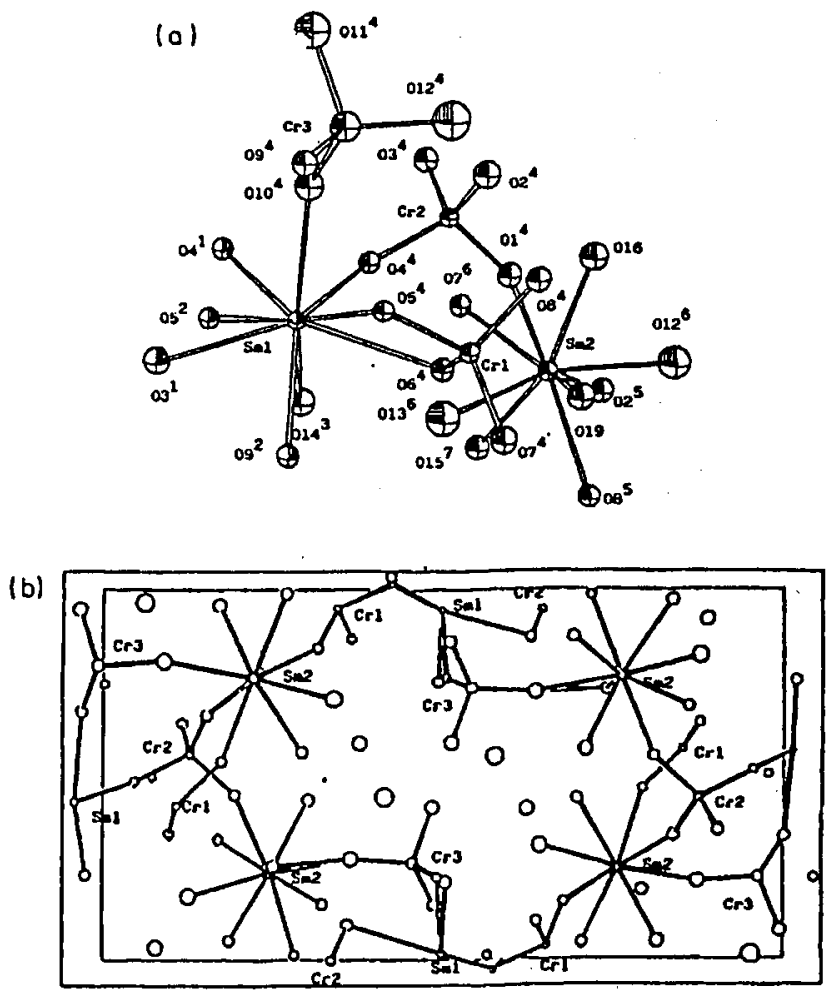

Fig. 1. (a) Coordination polyhedra of two samarium atoms in $\mathrm{Sm}_{2}\left(\mathrm{CrO}_{4}\right)_{3}, 7 \mathrm{H}_{2} \mathrm{O}$ (from Ref. [4]). (b) Unit cell of $\mathrm{Sm}_{2}\left(\mathrm{CrO}_{4}\right)_{3}, 7 \mathrm{H}_{2} \mathrm{O}$ (from Ref. [4]). 
TABLE I

Lattice parameter for the rare earth cliromates from Ref. [1-4].

\begin{tabular}{c|c|c|c|c}
\hline \hline & $a[\AA]$ & $b[\AA]$ & $c[\AA]$ & $\beta^{\circ}$ \\
\hline $\mathrm{KLa}\left(\mathrm{CrO}_{4}\right)_{2}$ & 8.729 & 7.475 & 11.049 & 92.42 \\
$\mathrm{KEu}\left(\mathrm{CrO}_{4}\right)_{2}$ & 13.844 & 5.749 & 9.048 & - \\
$\mathrm{La}(\mathrm{OII}) \mathrm{CrO}_{4}$ & 4.723 & 13.222 & 7.019 & 107.28 \\
$\mathrm{Sm}_{2}\left(\mathrm{CrO}_{4}\right)_{3}, 7 \mathrm{H}_{2} \mathrm{O}$ & 7.95 & 19.02 & 10.42 & 90.7
\end{tabular}

\section{Analysis of the luminescence spectra}

\subsection{Experimental}

The luminescence spectra of different rare earth chromates in polycrystalline form were obtained under $457.9 \mathrm{~nm}$ excitation of a Spectra Physics 164 Ar-ion laser. A Spectra Physics 375/376 continuous wave dye laser (with rhodamine 6G as the dye) pumped by argon ion laser was used to excite selectively the lowest excited ${ }^{5} D_{J}$ level, ${ }^{5} D_{0}$. The emission of the europium ion, dispersed by $1-\mathrm{m}$ Jarrell Ash monochromator, was detected by a IIamamatsu R 374 photomultiplier in the visible region. All experiments were performed at liquid nitrogen temperature.

\subsection{Emission spectra}

For all rare earth chromates studied, the emission spectra of the trivalent europium ion embedded in the samples consists of numerous sharp lines. The ${ }^{5} D_{0}$ is the only emitting level. All the observed lines are assigned to the ${ }^{5} D_{0} \rightarrow{ }^{7} F_{0-4}$ electronic transitions. The luminescence from other ${ }^{5} D_{J}$ levels, $J=1,2$, is quenched. It is due to the multiphonon de-excitation process from upper ${ }^{5} D$ levels to the lowest ${ }^{5} D_{0}$ level, or to the quenching process due to high concentration of the active ion in the pure europium compounds. The overview of the $\mathrm{La}_{2}\left(\mathrm{CrO}_{4}\right)_{3}, 7 \mathrm{II}_{2} \mathrm{O}: \mathrm{Eu}^{3+}$ emission spectrum (Fig. 2) recorded from 500 to $750 \mathrm{~nm}$ show the ${ }^{5} D_{0} \rightarrow{ }^{7} F_{2}$ transition as the most intense one and it is valid for all rare earth chromates discussed in this work.

\section{3. $\mathrm{KLa}\left(\mathrm{CrO}_{4}\right)_{2}$}

The first luminescence study on the chromates has been performed on the lanthanum potassium double cliromate, doped with europium as the spectroscopic active ion. As expected from the structural determination, one energy level scheme was deduced from the emission spectrum [7]. The point site symmetry for the rare earth ion is low, $\left(C_{1}\right)$, the degeneracy of levels should be completely lifted in $2 J+1$ components for each $J$ manifold. The optical and the structural data are in agreement in this case since one, three and five Stark components are present for ${ }^{5} D_{0} \rightarrow{ }^{7} F_{0-2}$ transitions, respectively, for example. 


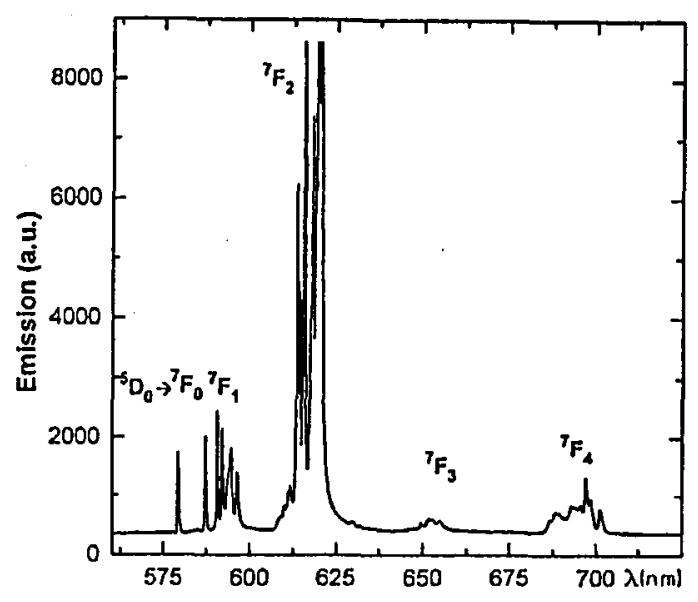

Fig. 2. Emission spectrum of $\mathrm{La}_{2}\left(\mathrm{CrO}_{4}\right)_{3}, 7 \mathrm{II}_{2} \mathrm{O}: \mathrm{Eu}^{3+}$ recorded at $77 \mathrm{~K}$ under $457.9 \mathrm{~nm}$ argon ion laser excitation.

$$
\text { 3.4. } \mathrm{K}(\mathrm{Eu}, \mathrm{Gd})\left(\mathrm{CrO}_{4}\right)_{2}
$$

For $\mathrm{K}(\mathrm{Eu}, \mathrm{Gd})\left(\mathrm{CrO}_{4}\right)_{2}$ compounds synthesized by hydrothermal technique or by solid state reaction, on the contrary, different emission spectra are obtained. In the case of $\mathrm{KEu}\left(\mathrm{CrO}_{4}\right)_{2}$ prepared by the solid state reaction two relatively intense lines are observed for the ${ }^{5} D_{0} \rightarrow{ }^{7} F_{0}$ transition, whereas for $\mathrm{KGd}\left(\mathrm{CrO}_{4}\right)_{2}: \mathrm{Eu}^{3+} 1 \%$ only one exists. It means two point sites for the stoichiometric europium compound, or an additional impurity phase, and one local symmetry environment in the case of the gadolinium potassium chromate. Moreover, for $\mathrm{KEu}\left(\mathrm{CrO}_{4}\right)_{2}$ prepared by the hydrothermal method several extra lines are present in the emission spectrum (upper spectrum (a) in Fig. 3). From the crystallographic investigation the same structure was found for both compounds. In fact, the X-ray spectra collected in Fig. 4 are identical for the europium and the gadolinium chromates synthesized using direct solid state reaction. Some new intense diffraction lines (noted by * on the lowest diffraction pattern in Fig. 4) are present for the europium chromate synthesized by the hydrothermal method. The $\mathrm{KEu}\left(\mathrm{CrO}_{4}\right)_{2}$ synthesized by hydrothermal technique seems to be dimorphic, but this extra phase is not identified yet.

In order to clarify the discrepancy between the structural and optical data for double chromates prepared by direct solid state reaction, $\mathrm{K}\left(\mathrm{Eu}_{x} \mathrm{Gd}_{1-x}\right)\left(\mathrm{CrO}_{4}\right)_{2}$ compounds with various concentrations of the doping ion $(x=0.01,0.03,0.05$ and 1) are studied by luminescence spectroscopy. It is evident from Fig. 5 that at very low concentration of europium, (lower trace d), the extra spectrum disappears, the remaining one corresponds to the rare earth in one local point site in $\mathrm{KGd}\left(\mathrm{CrO}_{4}\right)_{2}$ chromate as stated by the crystallographic study [2]. The relative intensity of the second spectrum increases with the the doping ion concentration. The extra spectrum does not correspond to the one observed in $\mathrm{KLa}\left(\mathrm{CrO}_{4}\right)_{2}: \mathrm{Eu}^{3+}[7]$. This indicates a new phase, whereas no clear difference is seen from X-ray diffrac- 

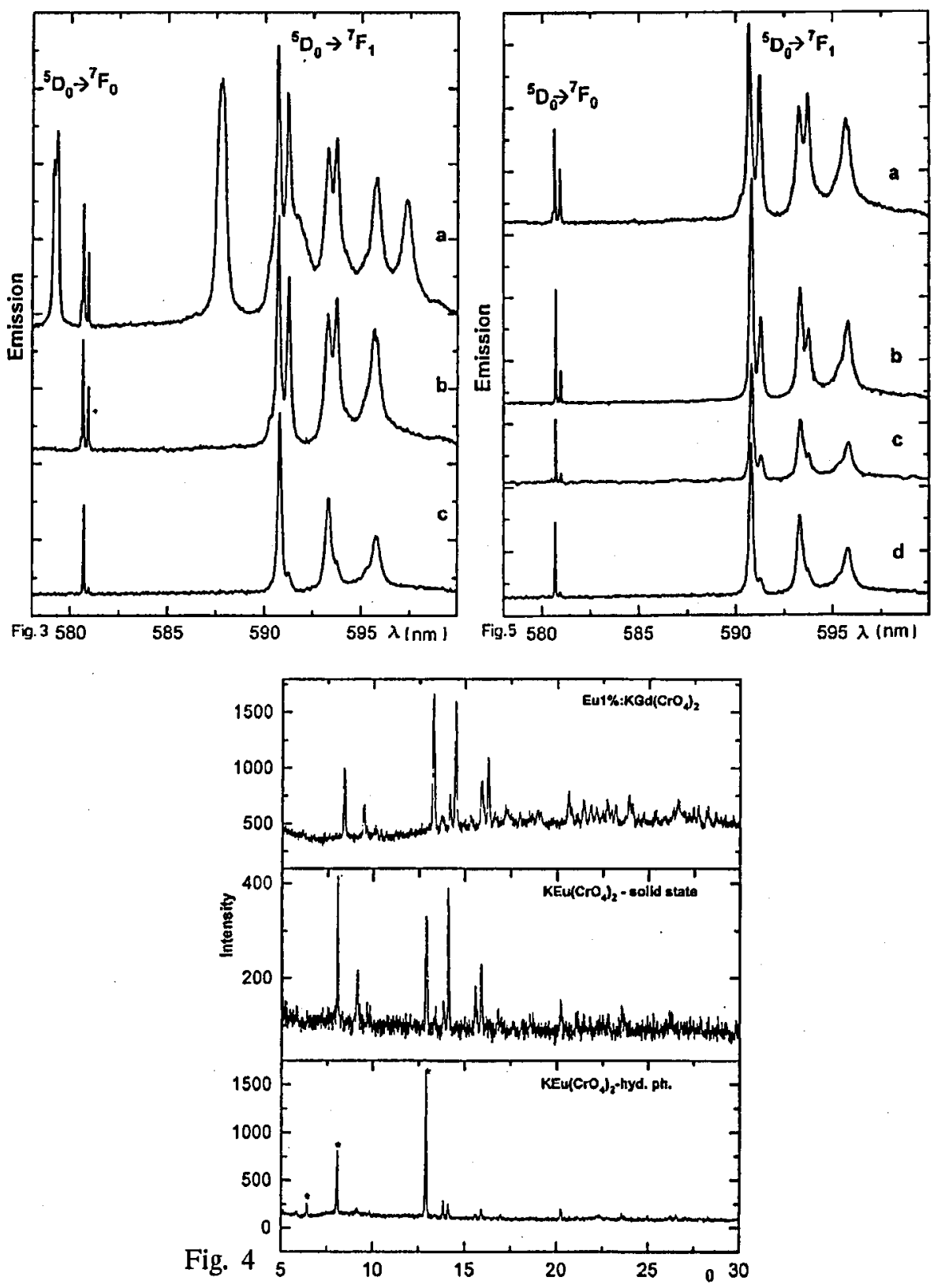

Fig. 3. A part of the emission spectrum of pure $\mathrm{KEu}\left(\mathrm{CrO}_{4}\right)_{2}$; hydrothermal synthesis method (a) and solid state reaction (b) and $\mathrm{KGd}\left(\mathrm{CrO}_{4}\right)_{2}: \mathrm{Eu}^{3+} 1 \%$ solid state reaction (c) recorded at liquid nitrogen temperature.

Fig. 4. X-ray diffraction patterns of $\mathrm{KGd}\left(\mathrm{CrO}_{4}\right)_{2}: \mathrm{Eu}^{3+} 1 \%$ and $\mathrm{KEu}\left(\mathrm{CrO}_{4}\right)_{2}$.

Fig. 5. Fluorescence spectra for different europium concentrations in $\mathrm{KGd}\left(\mathrm{CrO}_{4}\right)_{2} 1$,

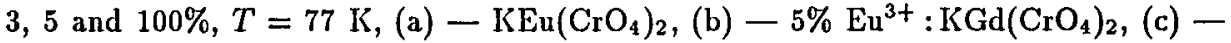
$3 \% \mathrm{Eu}^{3+}: \operatorname{KGd}\left(\mathrm{CrO}_{4}\right)_{2}$, (d) $-1 \% \mathrm{Eu}^{3+}: \mathrm{KGd}\left(\mathrm{CrO}_{4}\right)_{2}$. 
tion for the compounds synthesized by solid state reaction, or some effects of pair between europium ions, or other interactions. The question is still open. This first approach indicates that the europium ion is situated in all this family chromates in very low symmetry site.

Spectroscopic study performed on $\mathrm{KEu}\left(\mathrm{CrO}_{4}\right)_{2}$ samples prepared by two techniques, as well as on the doped $\mathrm{KGd}\left(\mathrm{CrO}_{4}\right)_{2}$ compounds, underlines the difference with the crystallographic analysis. A more detailed study is necessary.

\section{5. $\mathrm{RE}(\mathrm{OH}) \mathrm{CrO}_{4}$}

For this series we studied the lanthanum hydroxo-chromate doped with the europium trivalent ion. From the emission spectra it is evident that the rare earth ion occupies one point site in that structure and confirms the crystallographic data [3]. As the point site symmetry of the rare earth ion is very low, $C_{1}$, no selection rules exist. In this case, all transitions are allowed and the ${ }^{7} F_{1,2,4}$ levels are split in 3,5 and 9 Stark sublevels, respectively, see Fig. 6 for ${ }^{5} D_{0} \rightarrow{ }^{7} F_{0.1}$ transitions. In the region of the ${ }^{5} D_{0} \rightarrow{ }^{7} F_{3}$ transition some broad vibronics are observed and only four from seven components can be assigned to the ${ }^{7} F_{3}$ level. One energy level scheme for $\mathrm{Eu}^{3+}$ can be deduced from the luminescence spectrum. The experimental ${ }^{7} F_{0,1}$ energy levels are only used for determination of the phenomenological crystal field (CF) parameters of rank 2 and the CF strength parameter, $N_{v}$ (see Sec. 4). The results are gathered in Tables II and III.

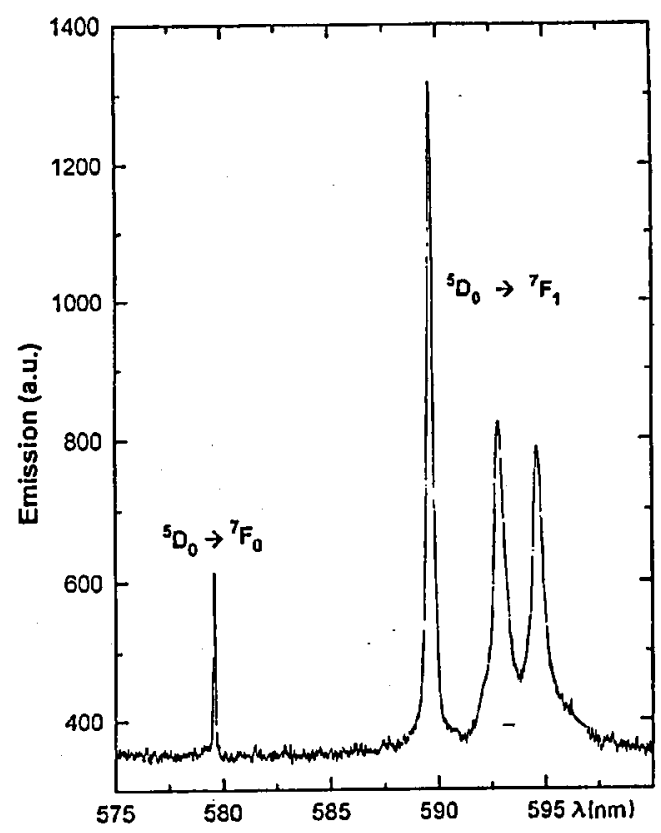

Fig. 6. A part of the emission spectrum of $\mathrm{La}(\mathrm{OH}) \mathrm{CrO}_{4}: \mathrm{Eu}^{3+}$ under $457.9 \mathrm{~nm}$ excitations, $T=77 \mathrm{~K}$. 


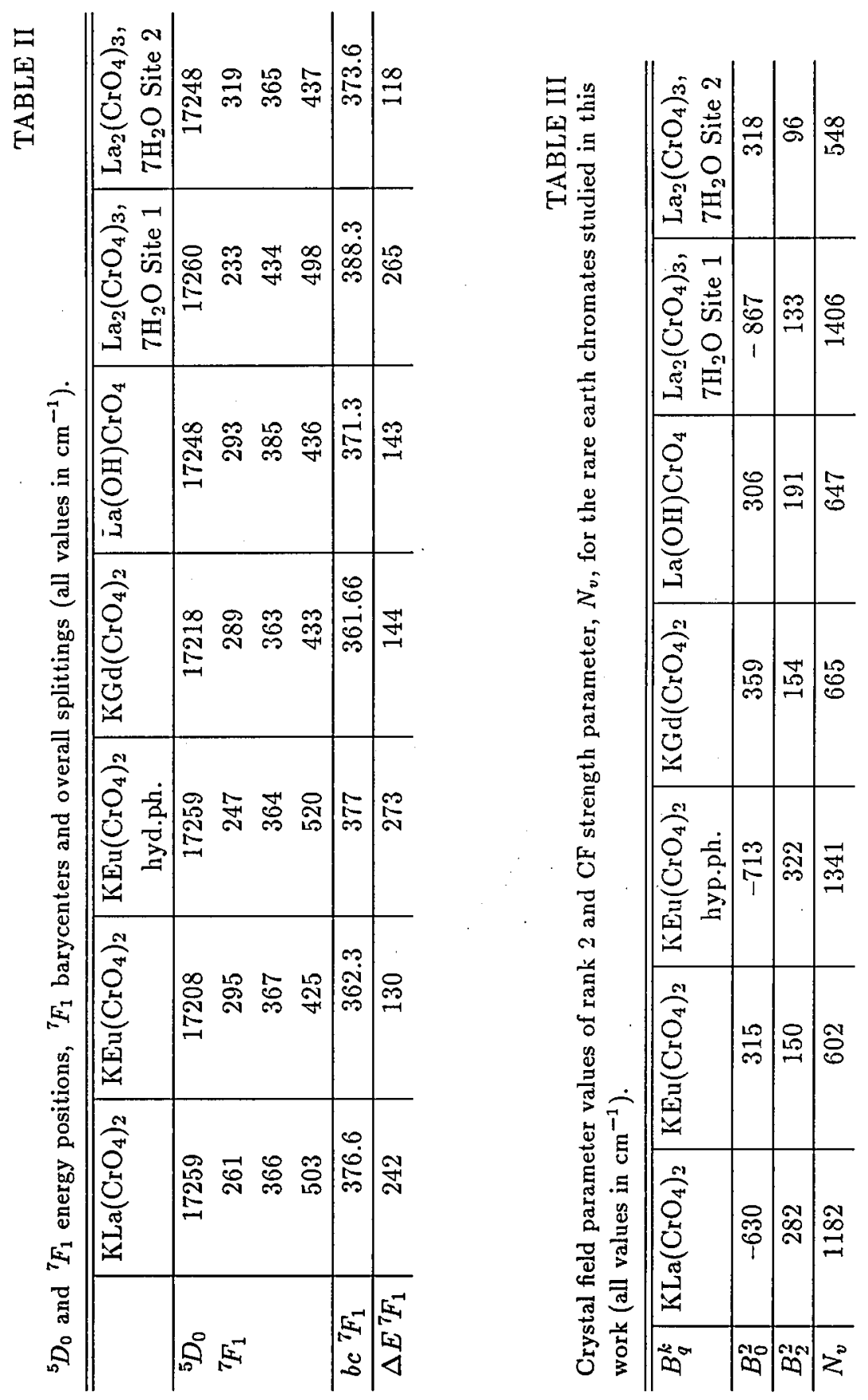




\section{6. $R E_{2}\left(\mathrm{CrO}_{4}\right)_{3}, 7 \mathrm{H}_{2} \mathrm{O}$}

We also analysed the luminescence of the europium embedded in the first chromate of that isostructural series, $\mathrm{La}_{2}\left(\mathrm{CrO}_{4}\right)_{3}, 7 \mathrm{H}_{2} \mathrm{O}: \mathrm{Eu}^{3+}$. Two different local environments are present for the rare earth ion in that crystallographic phase as it is shown in Fig. 7. This confirms the structural determination given in Ref. [4].

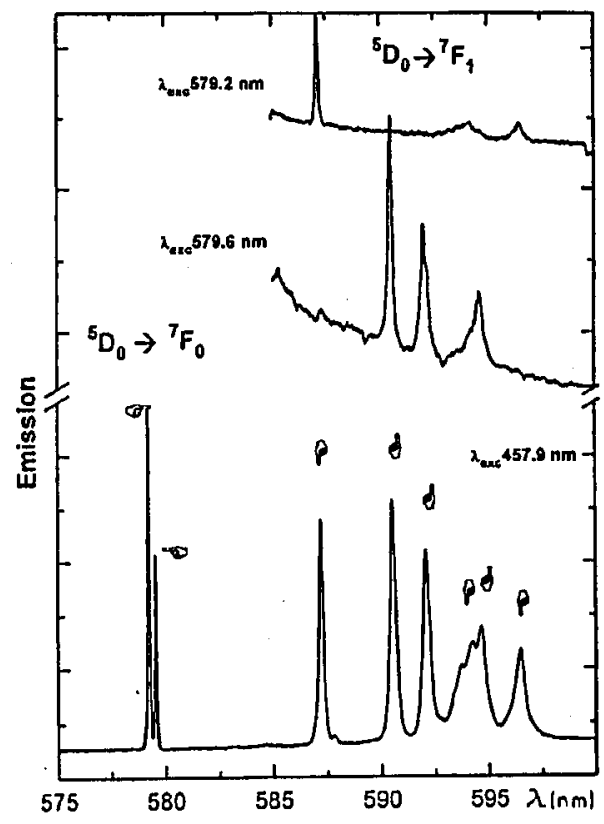

Fig. 7. A part of the emission spectrum of $\mathrm{La}_{2}\left(\mathrm{CrO}_{4}\right)_{3}, 7 \mathrm{H}_{2} \mathrm{O}: \mathrm{Eu}^{3+}$ under various excitations, $T=77 \mathrm{~K}$.

The selective excitation in the two 0-0 lines observed for $\mathrm{La}_{2}\left(\mathrm{CrO}_{4}\right)_{3}, 7 \mathrm{I}_{2} \mathrm{O}: \mathrm{Eu}^{3+}$ allows us to separate two different energy level schemes. They are associated to sites with quite different crystal field strengths. According to the structural determination both sites correspond to rare earth atoms in low symmetry environment, $C_{1}$. Then, $2 J+1$ Stark sublevels are expected for ${ }^{7} F_{J}$ manifolds, as explained in sections 3.3. and 3.5. In fact, numerous extra lines observed in the emission spectrum are identified as vibronics associated to ${ }^{5} D_{0} \rightarrow{ }^{7} F_{2}$ and ${ }^{5} D_{0} \rightarrow{ }^{7} F_{3}$ transitions. The appearance of these vibronics complicates the assignment of the electronic lines and for some $J$ levels some components are missing. All $M_{J}$ sublevels are found for the ${ }^{7} F_{1}$ level for both sites, whereas for the ${ }^{7} F_{2}$ level we observed all components only for site 2 . From the overall splittings of ${ }^{7} F_{1}$ levels, 265 and $118 \mathrm{~cm}^{-1}$ for site 1 and site 2, respectively, it is obvious that the crystal field strengths are different for two rare earth ions. It is discussed more in detail in Sec. 4 treating the CF simulation.

Some consideration can be done on the energy nosition of the ${ }^{5} D_{0} \rightarrow{ }^{7} F_{0}$ transition and the rare earth coordination in the chromates. For example, two in- 
tense lines observed for the ${ }^{5} D_{0} \rightarrow{ }^{7} F_{0}$ transition in $\mathrm{La}_{2}\left(\mathrm{CrO}_{4}\right)_{3}, 7 \mathrm{II}_{2} \mathrm{O}: \mathrm{Eu}^{3+}$ are situated at 17260 and $17248 \mathrm{~cm}^{-1}$ for site 1 and site 2, respectively. In the case of $\mathrm{KEu}\left(\mathrm{CrO}_{4}\right)_{2}$ double chromate (discussed in Sec. 3.4.) the positions of two lines detected for the ${ }^{5} D_{0} \rightarrow{ }^{7} F_{0}$ transition lie at lower energy: 17218 and $17208 \mathrm{~cm}^{-1}$. The rare earth coordination is different in these chromates. In the seven hydrated chromates both lanthanide ions are nine-fold coordinated and in the potassium double chromate the rare earth is eight-fold coordinated. In hydroxo-chromate (Sec. 3.5.), for which the rare earth is also surrounded by nine oxygen atoms, this transition is found at the same energy position as in the $\mathrm{La}_{2}\left(\mathrm{CrO}_{4}\right)_{3}, 7 \mathrm{H}_{2} \mathrm{O}$, as well as for the impurity phase present in the $\mathrm{KEu}\left(\mathrm{CrO}_{4}\right)_{2}$ compound (Sec. 3.4.) prepared by the hydrothermal synthesis method (see Table II). For this impurity phase the coordination of the rare earth is then supposed to be nine also. Moreover, from emission (upper spectrum, Fig. 3), it can be deduced that the local environment of the rare earth ion is very low, like in other chromates, but with greater crystal field strength.

\section{Crystal field simulation}

The trivalent europium ion, $4 f^{6}$ configuration, possesses a total of 3003 $|S L M J\rangle$ Stark levels for low symmetry sites. The particularity of this configuration is that the lowest level, ${ }^{5} D_{0}$, of the first excited ${ }^{5} D_{J}$ multiplet is situated at $12000 \mathrm{~cm}^{-1}$ far from the highest $J$ level of the ground ${ }^{7} F_{J}$ multiplet. So, the phenomenological CF simulation can be performed on the ground multiplet only, taking into account its 49 components. The wave functions are relatively pure, there is only a small admixture with the ${ }^{5} D$ and ${ }^{5} G$ states.

According to Wybourne's formalism, the crystal field Hamiltonian can be expressed as

$$
H_{\mathrm{cf}}=\sum_{k q}\left[B_{q}^{k}\left(C_{q}^{k}+C_{-q}^{k}\right)+\mathrm{i} S_{q}^{k}\left(C_{q}^{k}-C_{-q}^{k}\right]\right.
$$

with $B_{q}^{k}$ and $S_{q}^{k}$ being the real and imaginary CF parameters and $C_{q}^{k}$ the spherical harmonics [8].

In the case of $C_{1}$ local symmetry for the rare earth ion, there are $15 \mathrm{CF}$ parameters, 9 real and 6 imaginary ones. This large number of fitting parameters necessitates a great number of experimental levels [9]. For CF simulation in chromates an approaching symmetry, for example $C_{2 v}$ symmetry, can be used giving good results [7]. IIere, instead of 15 we deal with only 9 real CF parameters

$$
\begin{aligned}
& H_{\mathrm{cr}}\left(C_{2 v}\right)=B_{0}^{2}+B_{0}^{4}+B_{0}^{6}+B_{2}^{2}\left(C_{2}^{2}+C_{-2}^{2}\right)+B_{2}^{4}\left(C_{2}^{4}+C_{-2}^{4}\right) \\
& \quad+B_{2}^{6}\left(C_{2}^{6}+C_{-2}^{6}\right)+B_{4}^{4}\left(C_{4}^{4}+C_{-4}^{4}\right)+B_{4}^{6}\left(C_{4}^{6}+C_{-4}^{6}\right)+B_{6}^{6}\left(C_{6}^{6}+C_{-6}^{6}\right) .
\end{aligned}
$$

To evaluate the strength of the crystal field about the rare earth ion surrounded by its ligand cortege in various compounds, the crystal field strength parameter, $N_{v}$, is used, given by [10]

$$
N_{v}=\left[\sum_{k q} \frac{4 \pi}{2 \kappa+1}\left|B_{q}^{k}\right|^{2}\right]^{1 / 2} .
$$


From the emission spectra of chromates studied, the only observed level assigned with no doubt for all of them, is the ${ }^{7} F_{1}$ level. Therefore, we are interested in the ${ }^{7} F_{1}$ manifold and the phenomenological $C F$ calculation is performed taking into account only the $B_{0}^{2}$ and $B_{2}^{2}$ parameters. For the $J=1$ value, the CF strength parameter $N_{v}$ is then

$$
N_{v}=\left[\frac{4 \pi}{5} \sum_{q}\left|B_{q}^{k}\right|^{2}\right]^{1 / 2} .
$$

In Table III one can found the CF parameter values of rank 2 deduced from the experimental optical data and the CF strength parameter $N_{v}$. The evolution of the overall ${ }^{7} F_{1}$ splitting in function of $N_{v}$ is presented in Fig. 8. This parameter classifies the compounds according to their crystal field extent. In chromate family, two groups are constituted, with small or medium $N_{v}$ values and the largest $N_{v}$ values as it is explicit from Fig. 8. The $N_{v}$ values calculated for various chro-

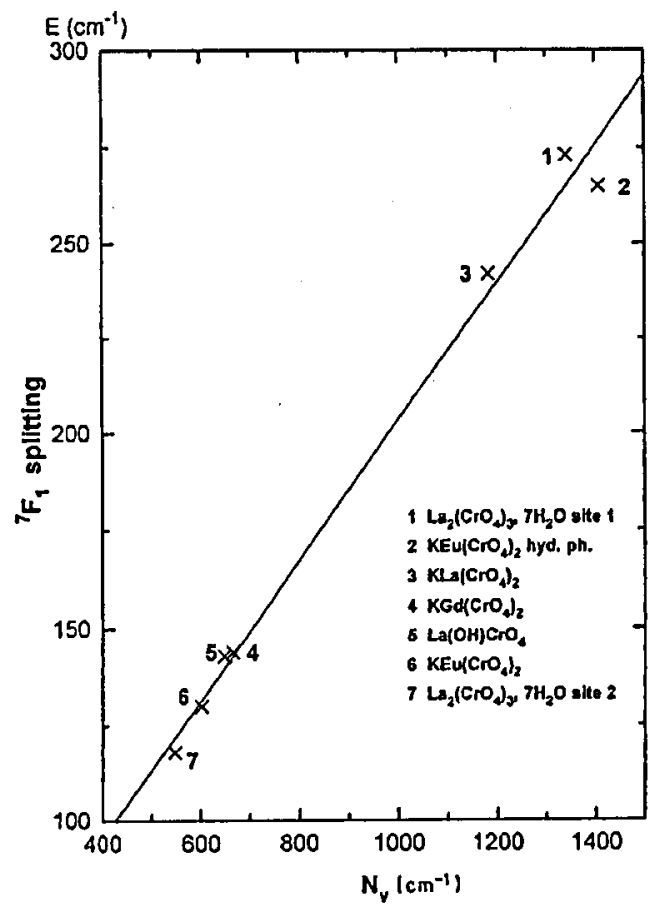

Fig. 8. The CF strength parameter $N_{v}$ in function of the overall ${ }^{7} F_{1}$ splitting.

mates are small in comparison with those found in the C-type rare earth oxide series, for example, for which $N_{v}$ is going from $1491 \mathrm{~cm}^{-1}\left(\mathrm{Gd}_{2} \mathrm{O}_{3}\right)$ to $2158 \mathrm{~cm}^{-1}$ $\left(\mathrm{Sc}_{2} \mathrm{O}_{3}\right)$ [11]. In fact, the maximum splitting of the ${ }^{7} F_{1}$ level is $273 \mathrm{~cm}^{-1}$ for the unknown phase in $\mathrm{KEu}\left(\mathrm{CrO}_{4}\right)_{2}$ synthesized by hydrothermal method (or $265 \mathrm{~cm}^{-1}$ 
for $\left.\mathrm{KLa}\left(\mathrm{CrO}_{4}\right)_{2}\right)$ instead of $461 \mathrm{~cm}^{-1}$ in $\mathrm{Sc}_{2} \mathrm{O}_{3}$. Therefore, the CF parameters of rank 2 in chromates are not high and it seems to be alike for other $\mathrm{CF}$ parameter values. This indicates the low potential of those compounds as efficient phosphors or for laser application.

\section{Acknowledgments}

The authors wish to thank Dr. P. Porcher for providing CF calculation program.

\section{References}

[1] I. Bueno, C. Parada, O. Garcia, E. Gutiérrez Puebla, A. Monge, C. Ruiz Valero, J. Chem. Soc. Dalton Trans., 1911 (1988).

[2] I. Bueno, C. Parada, J.A. Ilermoso, A. Vegas, A. Martinez Ripoll, J. Solid State Chem. 85, 83 (1990).

[3] I. Bueno, C. Parada, E. Gutiérrez Puebla, A. Monge, C. Ruiz Valero, J. Solid State Chem. 78, 78 (1989).

[4] I. Bueno, C. Parada, A. Monge, C. Ruiz Valero, An. Quim. 87, 1050 (1991).

[5] C.K. Jorgensen, Chimica 38, 74 (1984).

[6] I. Bueno, C. Parada, A. Monge, C. Ruiz Valero, in: Proc. Latin-American Inorg. Chem. Meeting, Santiago de Compostela, Spain, Sept. 1993, p. 392.

[7] E. Antic-Fidancev, M. Lemaitre-Blaise, P. Porcher, I. Bueno, C. Parada, R. Saez Puche, Inorg. Chim. Acta 182, 5 (1991).

[8] B.G. Wybourne, Spectroscopic Properties of Ions in Crystals, Interscience, New York 1965.

[9] E. Antic-Fidancev, M. Lemaitre-Blaise, J.P. Chaminade, P. Porcher, J. Alloys Comp. 180, 223 (1992).

[10] F. Auzel, O.L. Malta, J. Phys. (France) 44, 201 (1983).

[11] O.L. Malta, E. Antic-Fidancev, M. Lemaitre-Blaise, A. Milicic-Tang, M. Taibi, $J$. Alloys Comp. 228, 41 (1995). 